\title{
Adaptations and Safety Modifications to Perform Safe Minimal Access Surgery (MIS: Laparoscopy and Robotic) During the COVID-19 Pandemic: Practice Modifications Expert Panel Consensus Guidelines from Academia of Minimal Access Surgical Oncology (AMASO)
}

\author{
S. P. Somashekhar ${ }^{1}$ (D) $\cdot$ Rudra Acharya $^{2} \cdot$ Avinash Saklani $^{3} \cdot$ Devendra Parikh $^{4} \cdot$ Jagdishwar Goud $^{5} \cdot$ Jagannath Dixit $^{6}$. \\ K. Gopinath ${ }^{7}$ - M. Vijay Kumar ${ }^{8} \cdot$ Rajesh Bhojwani $^{9} \cdot$ Sandeep Nayak $^{10} \cdot$ Subramaneswar Rao $^{11} \cdot$ Kiran Kothari $^{12}$. \\ K. Chandramohan ${ }^{13} \cdot$ Sharad Desai $^{14} \cdot$ Arnab Gupta $^{15}$
}

Received: 24 July 2020 / Accepted: 29 October 2020 / Published online: 18 November 2020

(C) Indian Association of Surgical Oncology 2020

\begin{abstract}
The pandemic of COVID-19 across the globe triggered national lockdowns hampering normal working for all the essential services including healthcare. In order to reduce transmission and safety of patients and healthcare workers, the elective surgeries have been differed. The visits to the hospitals for follow-ups and consultations received temporary halt. However, we cannot halt the treatment for cancer patients who may or may not be COVID-19 positives. These are emergencies and should be treated ASAP. Conducting emergency surgeries during pandemic like COVID-19 is challenge for surgeons and the entire hospital infrastructure. The available information about COVID-19 and its propensity of contamination through droplets and aerosol need some modifications for conducting surgeries successfully without contaminating the hospital buildings, protecting healthcare teams and the patient. With these objectives, some modifications in the operating theater including surgical techniques for minimal access, laparoscopy, and robotic surgery are proposed in this review article. This review article also discusses the safety measures to be followed for the suspected or confirmed COVID-19 patient and the guidelines and recommendations for healthcare teams while treating these patients. Although there is little evidence of viral transmission through laparoscopic or open approaches, modifications to surgical practice such as the use of safe smoke evacuation and minimizing energy device used to reduce the risk of exposure to aerosolized particles to healthcare team are proposed in this review article.
\end{abstract}

Keywords COVID-19 $\cdot$ SARS-CoV-2 $\cdot$ Minimally invasive surgery (MIS) $\cdot$ Personal protection equipment (PPEs)

S. P. Somashekhar

somashekhar.sp@manipalhospitals.com

Rudra Acharya

acharyarp@yahoo.com

Avinash Saklani

dr_saklani_surgeon@yahoo.com; asaklani@hotmail.com

Devendra Parikh

drdevendragp@gmail.com

Jagdishwar Goud

jagdishgdr@yahoo.com

Jagannath Dixit

drjagannath@gmail.com

K. Gopinath

drgopinath1@hotmail.com

M. Vijay Kumar

mvijai2002@yahoo.com
Rajesh Bhojwani

docbhojwani@gmail.com

Sandeep Nayak

nayak.dr@gmail.com

Subramaneswar Rao

subramanyesh@gmail.com

Kiran Kothari

kckothari@gmail.com

K. Chandramohan

drchandramohan@gmail.com

Sharad Desai

drsharaddesai@gmail.com

Arnab Gupta

drarnabgupta1@gmail.com

Extended author information available on the last page of the article 


\section{Introduction}

COVID-19 pandemic has brought the world to a standstill with national lockdowns. The risks of contracting COVID19 are high among the populations and have adversely affected the clinical care for other serious health ailments. Cancer is one of them accounting for approximately more than 9.6 million deaths worldwide [1].

Cancer is a disease with high prevalence and mortality. Currently, the reported incidence in India is $>100,000$ new cases per month.

There are high chances of morbidity (40\%) and mortality $(20 \%)$ in patients after elective surgery in the face of COVID19 infection post-surgery. Cancer patients seem to be more vulnerable to COVID-19 posing further risks to their lives. [2]

It is not advisable to delay treatment for cancer patients, irrespective of their COVID-19 status as delay in surgical treatment adversely affects clinical outcomes and increases economic burden for the patient and the family. Additionally, spread of infection to surgeons and other health workers is high while operating on a patient of COVID-19 infection during this pandemic situation [3-5].

These challenging professional times must be tackled to effectively provide the treatment that patients deserve to receive. This review article discusses various aspects of conducting MIS with few modifications in the surgical practices and techniques during these challenging times to minimize the risks of contamination of the healthcare facilities, healthcare teams, and safety of the patients.

\section{Literature Review, Guideline Recommendations, and Scope of this Review Article}

COVID-19 pandemic has prompted medical fraternity and the affiliated societies to quickly reconcile to the fact that COVID-19 is highly contagious and operating without proper safety majors is a risky proposition for patients as well as to the healthcare teams. Hence, all elective surgeries have been suspended. The professional bodies of the surgical fraternity have been quick to respond to this emerging situation with recommendations that would benefit the members to review the current surgical practices, to modify the practices to prevent chance of contamination to be able to deliver emergency medical care for patients.

Several societies have released recommendations such as the Indian Association of Surgical Oncology (IASO), Association of Minimal Access Surgeons of India (AMASI), Society of American Gastrointestinal and Endoscopic Surgeons (SAGES), European Association of Endoscopic Surgery (EAES), EAU Robotic Urology Section (ERUS), Association of PeriOperative Registered Nurses (AORN), and Inter Association Surgical Practice Recommendations
(AMASI, IAGES, and SELSI) and all insist on the safety of the healthcare professionals, support teams, and the safety of medical infrastructure from COVID-19 [5-10].

Although MIS includes minimum direct contact with the body tissues, generation of smoke and aerosolized particles contaminating the operating theaters (OTs) and risking healthcare team exists. Therefore, identification of potential risks and suggestive remedies to reduce this risk is the main objective of this paper.

Generation of $\mathrm{CO}_{2}$ during the procedure is considered as major risk of virus transmission. A surgical smoke evacuator (open, laparoscopic, or robotic) as well as self-maintained constant pneumoperitoneum system is recommended. Smoke evacuation and filtration of the $\mathrm{CO}_{2}$ generation is recommended to minimize chance of contamination.

The chances of COVID-19 infection to the healthcare teams during MIS (laparoscopic or robotic) are considered low (Table 1). However, it is advised to strictly follow the protective methods to reduce the risk of COVID-19 infection to surgical staff in the OT room. Therefore, an assumption that few patients with suspect/confirmed COVID-19 will require surgical procedures during the ongoing pandemic is justified. This review article focuses on various domains of MIS (lap and robotic) that need attention and modification while operating during the Pandemic of COVID-19. (Table 2).

\section{Domains of MIS}

MIS procedures do not require direct access to the patients; however, there are several areas that could be potentially dangerous for spread of infection. Therefore, in this review articles, the various main domains of the MIS are classified (Fig. 1), and remedial alternatives to prevent risk of contamination are proposed. All these aspects are directed towards a single goal (patient safety, HCP safety while addressing emergencies during COVID-19).

\section{Patients}

All the patients requiring surgery must be screened for the presence/absence of COVID-19 prior to the surgery. The outcome has no bearing of delaying the procedure. It is mandatory to collect details such as the travel history, contact history, and respiratory symptoms/fever of the patient and that of the caretaker. Patient consent and that of the legal representative with complete knowledge and awareness about the risk of COVID-19 exposure and potential consequences, as well as the benefits and risks of surgery and the dangers of delaying the surgery must be addressed. Currently, there are 4options available for pre-op screening such as real time RT-PCR (real time reverse transcription-polymerase chain reaction, Rapid antibodies test, and HRCT and the recently available rapid antigen test. RT-PCR is the most accurate of all $[11,12]$. 
Table 1 Benefits and risks of surgical approach (robot assisted, conventional laparoscopic, and open surgery) under COVID-19 times

\begin{tabular}{|c|c|c|c|}
\hline Area of risk & Robot-assisted surgery & Conventional laparoscopy & Open surgery \\
\hline Aerosol escape & $\begin{array}{l}\text { Intra-abdominal dispersion, } \\
\text { limited by filters or locks } \\
\text { (no data on actual COVID-19 risk) }\end{array}$ & $\begin{array}{l}\text { Intra-abdominal dispersion, } \\
\text { limited by filters or locks } \\
\text { (no data on actual COVID-19 } \\
\text { risk) }\end{array}$ & $\begin{array}{l}\text { Less aerosol formation, unconfined } \\
\text { dispersion, unfiltered. } \\
\text { Only present, but that unfiltered } \\
\text { and with maximal } \\
\text { exposure, when using electrical } \\
\text { and } \\
\text { especially ultrasonic devices } \\
\text { (no data on actual COVID-19 } \\
\text { in risk) }\end{array}$ \\
\hline Smoke & $\begin{array}{l}\text { Confined, filtered, and less than } \\
\text { at open surgery }\end{array}$ & $\begin{array}{l}\text { Confined, filtered, and less than } \\
\text { at open surgery }\end{array}$ & Maximum exposure to smoke \\
\hline Blood, body fluids & $\begin{array}{l}\text { Hardly if any blood loss and } \\
\text { exposure at limited intervals }\end{array}$ & $\begin{array}{l}\text { Hardly if any blood loss and } \\
\text { exposure at limited intervals }\end{array}$ & $\begin{array}{l}\text { More blood loss and constant } \\
\text { exposure }\end{array}$ \\
\hline Abdominal pressure & $\begin{array}{l}\text { Minimal pressure (less than at } \\
\text { conventional laparoscopy). } \\
\text { Less than } 10 \mathrm{mmHg}\end{array}$ & $10-15 \mathrm{mmHg}$ & No abdominal pressure $(0 \mathrm{mmHg})$ \\
\hline $\begin{array}{l}\text { Perioperative cleaning of } \\
\text { instruments }\end{array}$ & $\begin{array}{l}\text { Large surface of robot to disinfect, } \\
\text { but limited number of instruments } \\
\text { to clean of limited blood } \\
\text { contamination }\end{array}$ & $\begin{array}{l}\text { Limited number of instruments } \\
\text { to clean of limited blood } \\
\text { contamination }\end{array}$ & $\begin{array}{l}\text { Only instrument to clean but these } \\
\text { in large number and severely } \\
\text { contaminated with blood }\end{array}$ \\
\hline Healthcare staff & $\begin{array}{l}\text { Usually one staff at the bedside, } \\
\text { one staff away from the patient } \\
\text { (remote) }\end{array}$ & Usually three staff at the bedside & Usually three staff at the bedside \\
\hline Hospital stay & Short & Short & Long \\
\hline
\end{tabular}

\section{General Measures to Reduce Transmission}

Institutional infection prevention practices should be established, practiced, revised, and validated for its effectiveness. Standard preventive measures need to be carried out by surgeons to protect oneself and patients as well as to minimize the contamination. The chances of COVID-19 infection to staff during surgery (open, laparoscopic, or robotic) are high. It is advised to reduce the risk of COVID-19 infection to surgical staff in the OT room by strictly following the using the protective methods [13].

Surgeons must avoid contact with droplets and use full body protection. Universal protection with PPEs (appropriate gowns, N95/FFP2-3 masks and face shields/goggles) is strongly recommended. [3, 10, 14] Donning of PPE should be done in the OT room and doffing should be done in wash area. OT footwear should be washed with soap and water immediately after the surgery. [7] The inability to completely and effectively control aerosolization of virus during endoscopic procedures exists, hence regular handwashing and use of sanitizers and PPE are a must.

\section{OR Practices}

Air change cycles and use of high-efficiency particulate air (HEPA) filters to reduce the load of the virus in OR is an important aspect. For selection of HEPA filters and deciding on the air change cycle, understanding of the virus and knowledge of air filtration system available are necessary. (Fig. 2).

COVID-19 virus is approximately $0.125 \mu \mathrm{m}(125 \mathrm{~nm})$ in diameter. A HEPA filtration system plays an important role in protection against viral cross-contamination by capturing airborne coronaviruses.

It is advisable to dedicate an OT for conducting surgeries in COVID-19 positive/suspected cases to reduce crosscontamination between OTs. $[14,15]$ OT rooms should be preferably situated on one side of the hospital complex. [13] OT rooms for suspected or confirmed COVID-19 patients should be adequately filtered and ventilated with an integrated HEPA filter. Negative pressure rooms should be considered to decrease the contamination of the neighboring OT. [13, 14] Procedures in COVID-19 negative cases should also be followed with these general recommendations to reduce COVID-19 transmission [13, 14].

The hospital policy must focus on deploying optimum number of healthcare works without comprising on the quality of healthcare support services. No unnecessary movement should be allowed inside the OT room.[16] Intubation and extubation should take place in a negative pressure room. [17, 18] A high frequency of air changes ( $>20$ cycles per hour) speedily reduces the viral load in the OT room. Positive pressure ventilation should be avoided if possible. Extubation should follow the same precautions as intubation $[17,18]$.

Video laryngoscope (VL) is advised for intubation. The use of viral filter in the breathing circuit (intersurgical or 
Table 2 MIS (laparoscopy and robotic surgeries): surgical technique modifications during COVID-19 pandemic overall summary

Ports and tissue extraction

Pneumoperitoneum management

Energy devices

Aerosol management: practical steps for filtration

Incisions for ports should be as small as possible to allow for the passage of ports but not allow for leakage around ports.

Ports should be placed with the intent of reducing leakage around the ports and port valves should be functional or replaced.

Tissue extraction should be performed after elimination of the $\mathrm{CO}_{2}$ pressure and controlled evacuation of the $\mathrm{CO}_{2}$ plume.

Instrument exchange should be minimized.

Decreasing the insufflation pressure to the lowest level possible and still permit good visualization.

This will decrease the amount of $\mathrm{CO}_{2}$ under pressure and reduce inadvertent release.

All pneumoperitoneum should be safely evacuated via a filtration system before closure, trocar removal, specimen extraction, or conversion to open.

Finally, if a laparoscopic suction device is being used, this would ideally be connected to a filtered device with an ultra-low particulate air (ULPA) or high-efficiency particulate air (HEPA) filter and not to an in-room canister connected to wall suction.

Reducing the electrocautery settings, decreasing application time, and improving tissue moisture to reduce tissue charring and smoke formation.

Recommendations state to use the lowest setting possible and to avoid techniques that create unnecessary plume in the abdomen.

Ultrasonic devices such as harmonic scalpel create significant aerosol without desiccation of tissue, and potentially viral release, and should be used judiciously.

Use of monopolar electrosurgery, ultrasonic dissectors, and advanced bipolar devices should be minimized, as these can lead to particle aerosolization.

All pneumoperitoneum should be safely evacuated from the port attached to the filtration device before closure, trocar removal, specimen extraction, or conversion to open.

Once placed, ports should not be vented if possible

During desufflation, all escaping $\mathrm{CO}_{2}$ gas and smoke should be captured with an ultra-filtration system and desufflation mode should be used on your insufflator if available.

The patient should be flat, and the least dependent port should be utilized for desufflation.

Specimens should be removed once all the $\mathrm{CO}_{2}$ gas and smoke are evacuated.

Filtration devices: Airseal and similar devices with smoke filtration mode.

Local modifications suggested with examples.

Summary points:

1. Consent discussion with patients to cover the risk of COVID-19 exposure and the potential consequences is a must.

2. The best outcomes for all can be achieved when individual patient and local circumstances must be considered, along with surgical experience and judgment,

3. Reduce the Trendelenburg position time as much as possible. This minimizes the effect of pneumoperitoneum on lung function and circulation, to reduce pathogen susceptibility.

4. The principles of evidence-based medicine require "the conscious, explicit, and judicious use of the best available evidence to help decide for patient care."

$\mathrm{CO}_{2}$ carbon dioxide, $H E P A$ high-efficiency particulate air; $H M E$ heat and moisture exchanger, $M D T$ multidisciplinary team, $M I S$ minimum invasive surgery, $O T$ operation theater. The recommendations are correctly based on caution given the lack of understanding of how COVID-19 compares to other viruses regarding transmission and presence in $\mathrm{CO} 2$ during MIS. There is no current evidence to demonstrate COVID-19 in the CO2 plume created during MIS. Because of the uncertainty surrounding COVID-19 in the CO2 plume, measures to decrease viral exposure to the surgical team should be performed

thermovent HEPA) or heat and moisture exchanger (HME) filter is advised. These filters should be attached to endotracheal tube (ETT) before intubation and it should be intact. Filter to the expiratory end of circuit should also be installed.

It is reported that COVID-19 is present in the stools of COVID-19 patients, but its transmission during laparoscopic procedures is not known. Fecal-oral transmission for COVID19 has not been reported though it may be possible.[15, 19]
Therefore, it is better to minimize bowel handling and opening during surgical procedures to reduce the risk virus dissemination with $\mathrm{CO}_{2}$.[14] Although no evidence of COVID-19 transmission through the urine is demonstrated, [19, 20] however, urethral or ureteral catheterization during the laparoscopic and robotic procedures should be performed with caution, particularly if pneumoperitoneum is already induced.[14] 
Fig. 1 Safety domains of MIS during COVID-19 pandemic

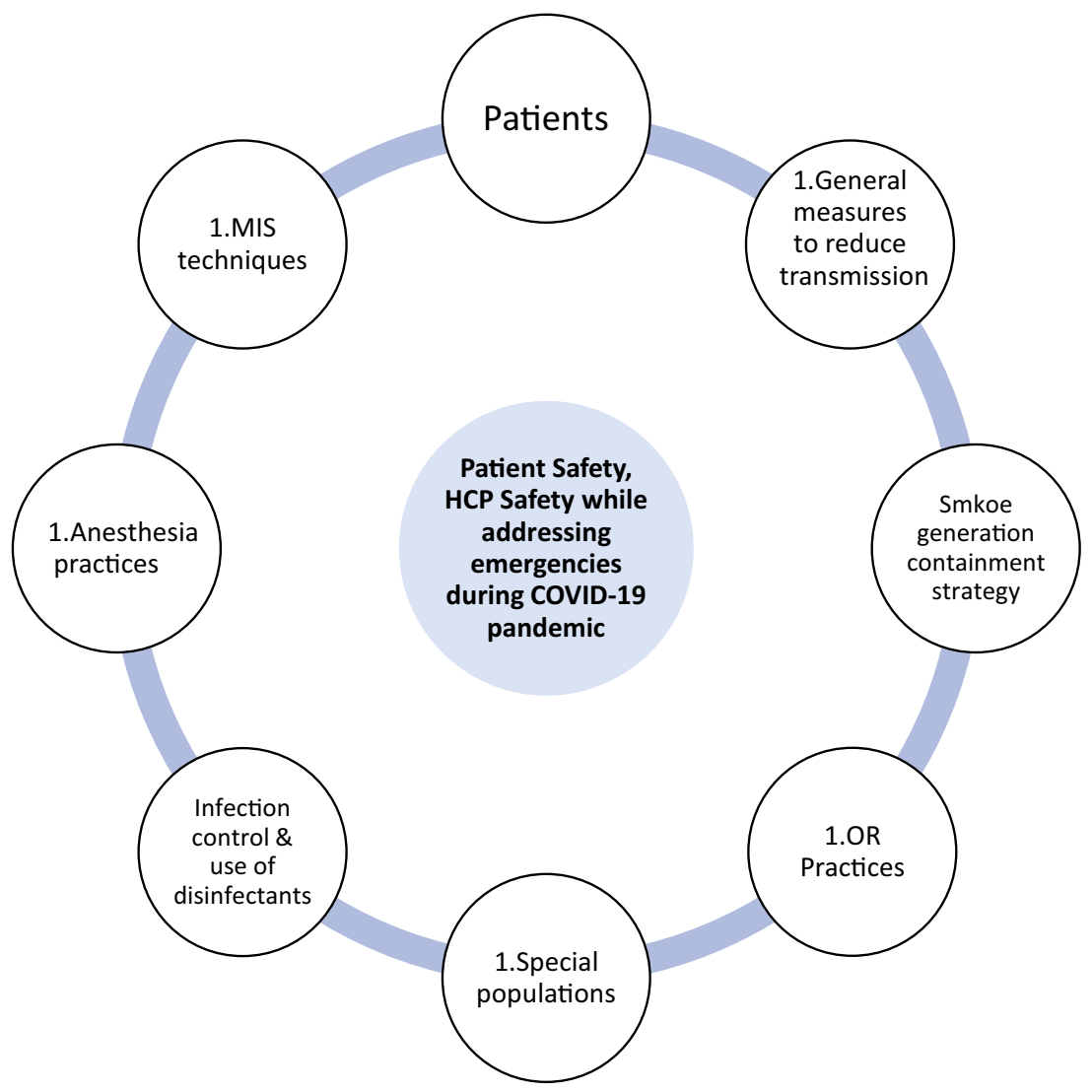

Endoscopic procedures requiring additional insufflation of carbon dioxide $\left(\mathrm{CO}_{2}\right)$ or room air should be avoided. Removal of caps on endoscopes should be avoided due to chances of release fluid or air.[13] Electronic gadgets such as pagers, laptop, or mobile and hospital case sheets should be left outside the OT rooms. Disposable pens should be used.[21]

Operation theaters should be prepared in advance for the procedure with adequate supplies and consumables including drugs, sutures, and emergency equipment prior to start of surgery.[7] The patients should be brought inside the OT room once all preparations are done. All MIS should be performed by experienced surgeons.[15] Only the anesthesia team should remain in the OT during intubation and extubation.

A proper OT exit pattern should be followed: surgical team, followed by patient after Extubation, followed by anesthesia team, followed by cleaning and sterilization team.

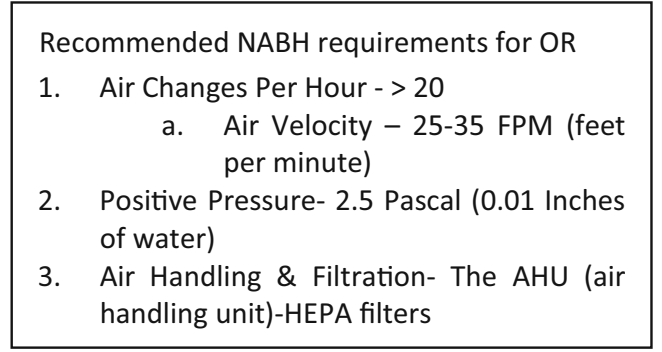

Fig. 2 Recommended NABH requirements for OR

\section{MIS Techniques}

A concern with the use of minimally invasive techniques has been raised due to a proposed risk of viral transmission of the coronavirus disease of 2019 (COVID-19) with the creation of pneumoperitoneum. Although risk of viral transmission could be considered theoretical in MIS (laparoscopy and robotic), it has some basis due to detection of COVID-19 virus RNA in the stool of infected patients suggesting that the virus can be found in the gastrointestinal mucosa. Therefore, a threat that the virus can be transmitted from the abdomen exists. It can be assumed that the environment created by pneumoperitoneum for laparoscopy creates a relatively stagnant heated volume of gas in the abdominal cavity which may subsequently allow for a concentrated aerosolization of the virus. Hence, the use of trocars must be carefully executed.

\section{Laparoscopic Trocar-Cannula Modifications}

Trocars are designed to cause minimal invasion to a patient requiring abdominal surgery. Due to high transmission of COVID-19, additional precautions need to be exercised using trocars in MIS (lap and robotic procedures) as these procedures use the same insufflators and smoke evacuation systems. Thus, sudden bursts of this pneumoperitoneum from trocar valves during exchange of instruments or during the 
venting of trocars can allow for transmission of the virus contaminating the OTs and risking the healthcare teams. Modifications in the surgical techniques that can lower pneumoperitoneum pressure as well as modification of trocar and canula techniques to minimize injuries and bursts can reduce potential contamination.

Several groups have demonstrated that traditional laparoscopic procedures can be performed with lower insufflation pressures than the standard $12-15 \mathrm{mmHg}$. Use of lower pneumoperitoneum pressures, when permissible, has low to no risk and has protentional advantage of reducing the volume of aerosolized particles.

The chance of laparoscopic instruments transmitting fomites and cross infection to staff and other patients is high. Incisions for ports should be appropriate to permit the passage of ports while preventing leakage around ports. [7, 9, 13] Once placed, ports should not be used for evacuation of smoke or for desufflation without taking adequate precautions.[9] Use of traditional trocars could be better due to the one-way valves within the proximal portion of the port. In robotic surgery, the leakage should be avoided from trocars when inserting $8-\mathrm{mm}$ or $5-\mathrm{mm}$ instruments through the $12-\mathrm{mm}$ trocars. The use of 5-mm instruments through even the $8-\mathrm{mm}$ trocars should perhaps be minimized [21].

$\mathrm{CO}_{2}$ insufflation pressure should be maintained at a minimum and an ultra-filtration system (smoke evacuation system or filtration) should be used. All pneumoperitoneum should be safely evacuated via a filtration system before closure, trocar removal, specimen extraction, or conversion to open [13].

\section{Smoke Generation Containment Strategy}

The risk of viral exposure during endoscopy and airway procedures is high. [22, 23] No reliable information about COVID-19 in MIS is currently available. However, I COVID-19 can be transmitted by droplets, contact, aerosol, and fecal-oral route and viral contamination can occur from aerosol formation. Ultrasonic scalpels or diathermy equipment used in MIS can produce huge amounts of surgical smoke, and the low temperature aerosol from ultrasonic scalpels or scissors cannot effectively deactivate the cellular components of virus in patients. [24] Due to previous reports of aerosolization of other viruses, $[25,26]$ COVID-19 infection should also be tackled during MIS procedures by the use of devices to filter released $\mathrm{CO}_{2}$ for aerosolized particles. [13] The smoke generation containment strategy focuses on the use of smoke evacuators, filters, and modifications in the use of diarthermy and energy devices.

\section{Smoke Evacuators}

Laparoscopic surgery can be performed managing gases using filtering aids such as a $\mathrm{CO}_{2}$ filter.[32] Standard electrostatic filters are expected to efficiently protect from the COVID-19 virus. These filters should be connected via standard tubing to the trocar evacuation port to evacuate the produced smoke and filter the possible viral load. [22] If a reliable filtering and evacuation system for gases is used, laparoscopy is preferable to open surgery, where smoke contamination is intense. Regular cleaning of instruments, evacuating pneumoperitoneum prior to removing trocars, and conversion or specimen extraction are particularly helpful. [23] The use of intelligent, integrated flow systems is recommended for the maintenance of low intra-abdominal pressure ensuring a self-maintained constant pneumoperitoneum. [7, 14, 16] Two-way pneumoperitoneum insufflators should be avoided to prevent pathogen colonization of circulating aerosol in the pneumoperitoneum circuit or the insufflator. The integrated flow systems should be configured in a continuous smoke evacuation and filtration mode, preferably through a ULPA filter. $[14,16]$

Complete desufflation of the pneumoperitoneum at the end of the surgical procedure should be ensured. Aerosol formed during the surgery may get concentrated in the abdominal cavity due to the enclosed gas in the pneumoperitoneum. [23] Integrated, active smoke evacuation systems are advised to prevent sudden bursts.[9] Conversely, traditional insufflation systems that are not equipped with active smoke evacuation mode or other filters may expose healthcare personnel to higher risk of COVID-19 aerosol transmission and should be avoided [14].

At Manipal Hospital, we have used an indigenous circuit devised from an HME filter (with or without HEPA filter) and an under-water seal using sodium hypochlorite solution for safe evacuation of pneumoperitoneum during COVID-19 response time (Fig. 3). This system is simple, disposable, quick to assemble, and efficient for smoke evacuation during laparoscopic procedures.

\section{Use of Filters}

Standard electrostatic filters (HME filters) used in ventilation machines can filter bacterial and viral loads with great efficacy. These filters may provide $>99 \%$ protection against hepatitis $\mathrm{C}$ virus (HCV) and hepatitis $\mathrm{B}$ virus (HBV) having a diameter of $>30 \mathrm{~nm}$. HEPA can remove up to $99.97 \%$ of contaminants $(\geq 0.3 \mu \mathrm{m}$ in diameter) and ULPA (ultra-low particulate air filters) up to $99.99 \%(\geq 0.12 \mu \mathrm{m})$.

Buffalo filter offers a wide line of filters and pre-filters to fit the surgical procedure requirements. Buffalo filter has 4 stages of filtration that ensure $99.999 \%$ efficiency for $0.1-0.2 \mu \mathrm{m}$ and HME filters provide bacterial and viral filtration above $99.9 \%$. Buffalo filter smoke evacuator tubing is connected to 2 HME filters and placed under the drape to provide air filtration. The use of multifilter system ensures maximum efficiency in filtering viral particles $[27,28]$. 


\section{Local Modifications - One example}
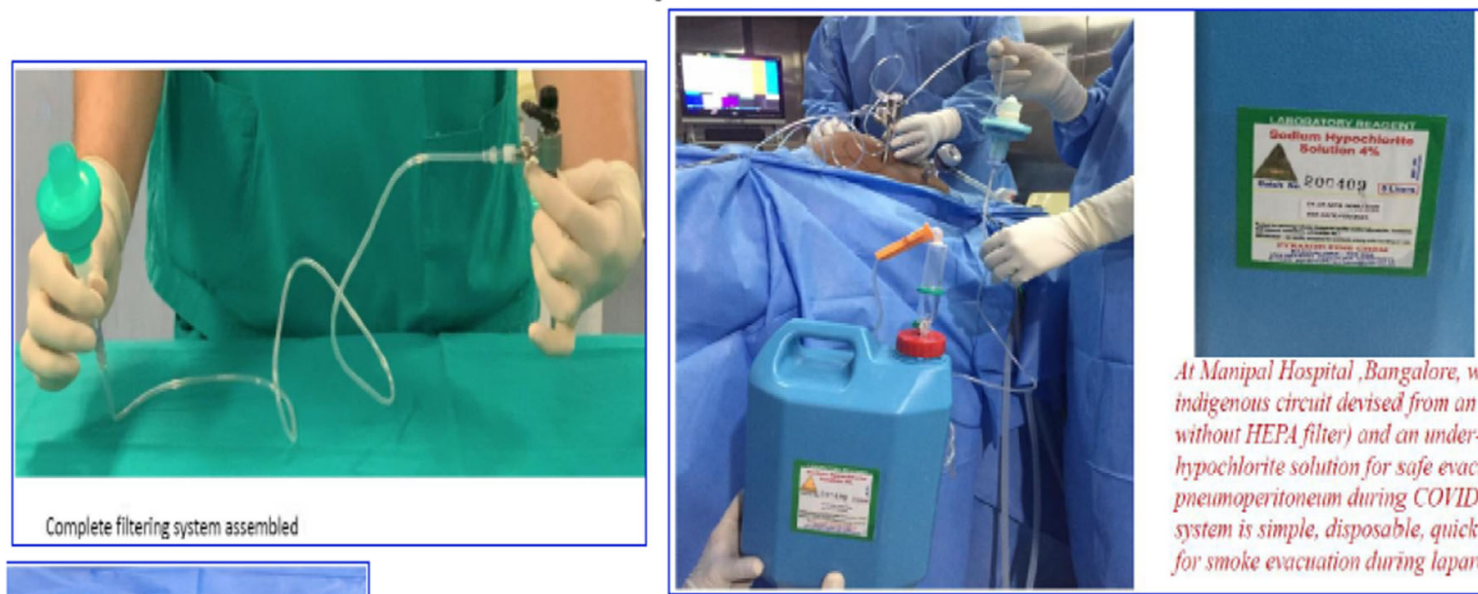

At Manipal Hospital, Bangalore, we have devised an. imaigenots circuit devised from an HME filter (with or without HEPA filter') and an under-water seal ising soditum hypochlorite solution for safe evacuation of pneumoperitoneum during COVID-19 response time. This system is simple, disposable, quick to assemble and efficient
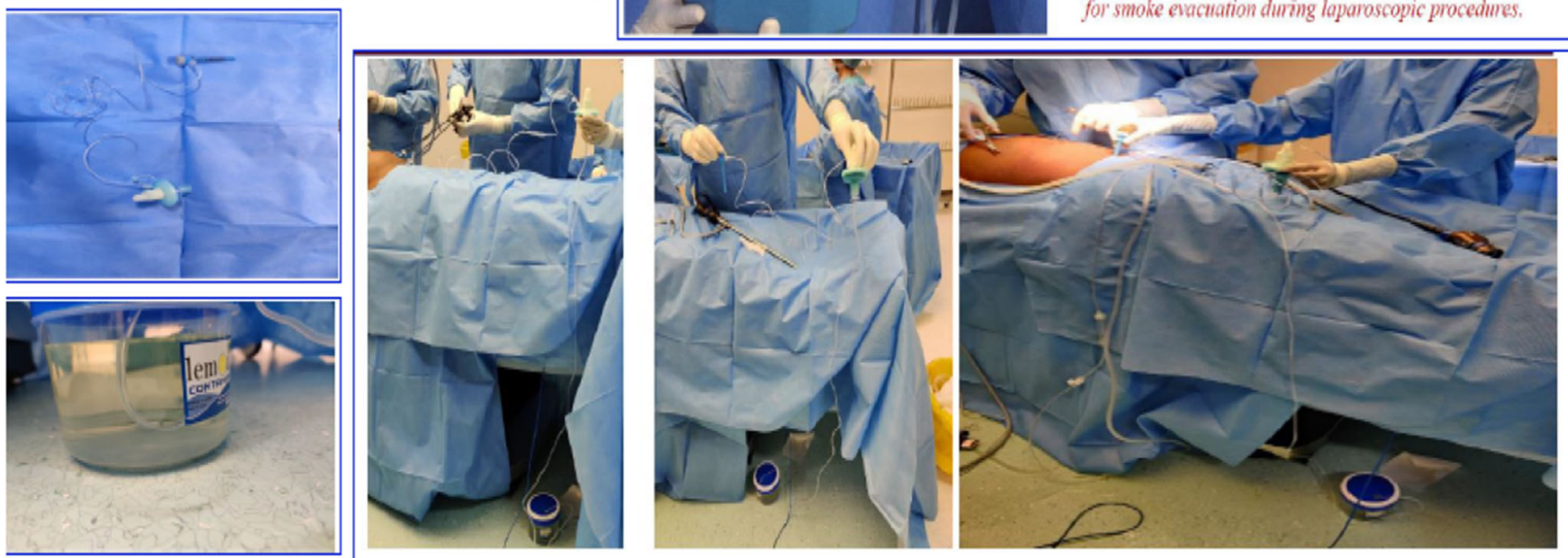

INTUITIVE.

Indian Manipal modification for lap evacuator under seal sodium hypochlorite during COVID-19 response time.

HEPA: High-efficiency particulate air; HME: Heat and moisture exchanger:

Fig. 3 Indigenous Manipal modification

\section{Modification in Diathermy Use to Reduce Aerosol and Smoke Generation}

Electrocautery should be used at the lowest effective power setting and should be escorted by suction. [5] Charring of tissues should be avoided to minimize the creation of smoke. [7] During both open and laparoscopic surgeries, the particle concentration may increase with use of energy sources. Use of monopolar electrosurgery, ultrasonic dissectors, and bipolar machines should be reduced due to possibility of particle aerosolization. [13] If unavoidable, monopolar diathermy pencils with attached smoke evacuators should be used. Energy devices should be minimally used. Cold hemostasis is the method of choice. [9] All the energy harmonic scalpel produces maximum aerosol and the bipolar scalpel produces the least. Therefore, the choice of scalpels is an important consideration of the smoke containment strategy.

Long dissecting times should be avoided on the same spot using energy devices to reduce surgical smoke. Suture closure devices for port closure that allow for leakage of insufflation should be avoided. [12] Needle stick and stab injuries should be avoided [5].

\section{Modification in Energy Device Use in Lap/Minimal Access Surgery}

Energy device produces plumes of surgical smoke. With the use of an energy device for $10 \mathrm{~min}$, the concentration of the smoke in laparoscopic surgery is higher than the open surgery. It may be due to the small volume of gas in the pneumoperitoneum. Thus, it is recommended to use electrocautery at the lowest power setting possible [14].

\section{Anesthesia Practices}

The goal is to minimize the aerosol-generating processes during general anesthesia to reduce chance exposure to patient's respiratory secretions and the risk of perioperative viral transmission to healthcare personnel and patients. [34] Intubation during general anesthesia may result in general aerosolization causing risk to anesthesia team as well as the OT personnel. Hence, preference should be given to regional anesthesia (open surgery) during surgical procedures [29, 30]. 
Laminar airflow or air conditioner should be started after induction of anesthesia. Laminar airflow or air conditioner should be stopped 20 min before the extubation. [9] After the surgery, the anesthetic breathing circuit and the container of soda lime should be discarded immediately. [21] Video laryngoscope (VL) is advised for intubation. The use of viral filter in the breathing circuit (intersurgical or thermovent HEPA) or heat and moisture exchanger (HME) filter is advised. These filters should be attached to an endotracheal tube (ETT) before intubation. Filter to the expiratory end of circuit should also be installed. Positive pressure ventilation should be avoided if possible. Extubation should follow the same precautions as intubation.

Neuraxial anesthesia may cause the risk of seeding infection into the central nervous system (CNS) in infected patients. Therefore, its use should be balanced against the risk of performing general anesthesia on patients with COVID-19. A pencil-point spinal needle is helpful for spinal anesthesia as it may reduce the risk of transmission viral material into the CNS. There is less tissue coring in comparison to cutting tip spinal needles [30].

\section{Infection Control and Use of Disinfectants}

Surgical equipment used for COVID-19 positive or suspected COVID-19 patients should be cleaned separately from other surgical equipment. All reusable contaminated material should be sterilized immediately.[7, 9] The monitor and cables of the VL should be cleaned with an alcohol-based sanitizer and kept in a UV chamber while the blade should undergo ethylene oxide (ETO) or plasma sterilization [7, 10].

Disposable materials only (such as gloves or paper towel) should be used for cleaning. Containers should be closed and sealed before transferring to the collection unit. [23, 24] There should be a gap of minimum of $1 \mathrm{~h}$ between two surgical procedures $[7,9]$.

Post-surgery, the OT should be cleaned with peroxyacetic acid/0.5-1\% sodium hypochlorite/glutraldehyde/ benzalkonium chloride/ultraviolet $\mathrm{C}$ irradiation for effective fumigation. $[5,7,21]$ Stretcher should be sprayed with $1 \%$ hypochlorite solution after shifting the patients. Sodium hypochlorite solution $1 \%$ should be used for cleaning OT tables and trolleys after shifting the patient. Post-surgery, all anesthesia equipment should be cleaned with $1 \%$ sodium hypochlorite solution. [9] All the surfaces of medical devices should be cleaned with quaternary ammonium chloride disinfectant.

Suction should be performed with two-bottle devices where one bottle should be filled with hypochlorite solution to allow the suctioned air/gas to pass through the solution before its evacuation into the second bottle. At the end of the procedure, complete desufflation should be done [5].

\section{Special Population}

Children are not severely affected by COVID-19 as per the available current information. [1,32] The infection is milder in pediatrics than in adults but pediatrics or children undergoing cancer treatment have a weakened immune system which will make it tougher for the body to fight off COVID-19 infection. These patients can serve as vectors in disease transmission.

All the recommendations suggested for adults are therefore applicable for pediatric patients. The goal should be to provide timely surgical care to pediatrics with critical issues while optimizing patient care resources (e.g., hospital and ICU beds, PPE and ventilators) and preserving the health of healthcare team.

\section{Discussion}

COVID-19 will not disappear anytime soon and will be part and parcel of our lives in the foreseeable future. This has consequences on general healthcare services. All elective surgical and endoscopic cases are required to be postponed at the current time. In COVID-19 positive patients, the procedure should be postponed if not emergent. [6-10] The emergency medical services cannot be delayed as it has negative impact of the clinical outcome especially for the cancer patients. Hence, they must be carried out irrespective of the patient's COVID-19 status.

The effectiveness of the healthcare system is based on the health status of the healthcare professionals, support staff, and safety of the premises. Contaminations of any of these keys factors can jeopardize the entire healthcare system; in fact, higher the contaminations in the healthcare sector with the contagious virus can lead to collapse of the entire healthcare infrastructure. Therefore, during this period of fear and apprehensions, a practical safe method that can continue to address medical emergencies is the need of an hour including safeguarding the safety of the healthcare teams with adequate safety precautions. .

This review article is an attempt to provide practice insights into identifying all the aspects that are likely to be the areas of contamination during MIS (lap and robotic) and the possible remedial solutions to minimize them.

One of the first domains is the screening of the patient with accurate diagnostic along with details of contact and travel. Precise and ease of information to the patients with access for COVID-19 testing with minimalist time lag will reduce unnecessary movement of the patient and the caretakers in the hospital.

All the healthcare professionals support staff of the OR must be re-oriented to the revised practices for conducting emergency procedures during the pandemic. It is essential that all are aware about the ventilation system, HEPA filter 
capabilities, and air change cycles. A simple checklist should be available for reference. Display boards must re-emphasize the new norms of the OR practices.

This review article is in line with the numerous guidelines that have already been published related to the safety from COVID19 pandemic. The potential benefits of MIS include minimum direct contact with the body tissues and shorter duration of hospitalization with reduced footfalls in the hospital. On the other hand, the chances of aerosolized particles in open surgery are high. Based on these facts, the potential benefits and risks of the surgical approach should be carefully weighed when considering laparoscopic versus open approach [7, 27, 31-34].

A surgical smoke evacuator in each surgical approach (open, laparoscopic, or robotic) should be used. Self-maintained constant pneumoperitoneum system should be used. An adequate insufflation management system may enable the surgeon to operate at a low and stable pneumoperitoneum while minimizing the $\mathrm{CO}_{2}$ ventilation. Smoke evacuation through a ULPA/HME filter can minimize the need to vent $\mathrm{CO}_{2}$ during laparoscopic procedures. We have described an indigenous method of safe smoke evacuation. Smoke evacuation disposables should be kept close to the source of smoke generation. $[9,10]$ For continuous active smoke evacuation and filtration for surgical procedures, dual-lumen smoke evacuation filtration can also be used. Ancillary suction-assisted smoke evacuation devices can be used to reduce the risk of aerosolized particles. During desufflation, the escaping $\mathrm{CO}_{2}$ gas and smoke should be passed through an ultra-filtration system and desufflation mode should be used on insufflator. [7] The use of devices with smoke evacuation filters may have a role in reducing the diffusion of COVID-19 although there is no specific data demonstrating presence of the COVID-19 virus in the aerosol released during minimally invasive abdominal surgery. Based on these recommendations, apart from indigenous systems, the current options available for laparoscopy and robotic during MIS minimal access surgeries during COVID-19 pandemic include the following: Buffalo filter, CONMED AIRseal System, Coviden RapidVac ${ }^{\mathrm{TM}}$, and Smoke Evacuator System.

Currently, the best approach to tackle COVID-19 transmission during an open, laparoscopic endoscopic surgery is to use a multi-pronged approach, which includes proper room filtration and ventilation and use of appropriate PPE and smoke evacuation devices with a suction and filtration system. By following the recommendations from different guidelines and adapting to the local situations, one can tackle the COVID-19 pandemic during surgical intervention of urgent cases which cannot be delayed.

\section{Conclusion}

Our healthcare system needs to quickly acclimatize to this rapidly changing environment of the COVID-19 pandemic.
The next few months are crucial in alleviating the transmission of COVID-19 infection. Surgical treatment should be performed only for emergent, non-deferrable cases. In addition to surgical patients, healthcare workers should also protect themselves by following the guidelines while treating the surgical patients. Although there is little evidence of viral transmission through laparoscopic or open approaches, we still recommend modifications to surgical practice such as the use of smoke evacuation and minimizing energy device used to reduce the risk of aerosolized particle exposure to healthcare personnel. Therefore, it is necessary to follow best surgical practices by adhering to careful management plan and thoughtful methodology.

Acknowledgments The authors would like to acknowledge the manuscript writing assistance of Dr. Manjusha Rajarshi from Mumbai.

Funding The authors received academic grant for content writing from India Medtronic Pvt. Ltd.

Data Availability Data transparency: NA.

\section{Compliance with Ethical Standards}

Conflict of Interest The authors declare there they have no conflicts of interest.

Ethical Issues NIL.

Consent to Participate NA.

Code Availability (Software Application or Custom Code) NA.

\section{References}

1. WHO update: https://www.who.int/emergencies/diseases/novelcoronavirus-2019

2. Dai M, Liu D, Liu M et al (2020) Patients with cancer appear more vulnerable to SARS-COV-2: a multi-center study during the COVID-19 outbreak. Cancer Discov 282:20. https://doi.org/10. 1158/2159-8290.CD0422

3. IASO (Indian Association of Surgical Oncology). Updated IASO Covid-19 Guidelines. - 16th April 2020. Available at: https:// iasoindia.in

4. Patel R, Babady E, Theel ES, Storch GA, Pinsky BA, George KS et al (2020) Report from the American Society for Microbiology COVID-19 International Summit, 23 March 2020: Value of diagnostic testing for SARS-CoV-2/COVID-19. mBio 11(2)

5. Al-Muharraqi MA (2020) Testing recommendation for COVID-19 (SARS-CoV-2) in patients planned for surgery - continuing the service and 'suppressing' the pandemic. Br J Oral Maxillofac Surg S0266-4356(20):30164-30169

6. Inter Association Guideline. Inter association surgical practice recommendations in COVID 19 Era (for minimal access surgeons in India). 23rd April 2020.

7. AMASI (Association of Minimal Access Surgeons of India). AMASI guideline for conducting minimal access surgery during COVID-19 pandemic. 2020. Available at: https://www.amasi.org/ 
8. ERUS (EAU Robotic Urology Section) Guideline 2020. Available at: https://uroweb.org/wp-content/uploads/ERUS-guidelines-forCOVID-def.pdf

9. EAES and SAGES Guideline 2020. Recommendations regarding surgical response to COVID-19 crisis. Released 30-Mar-2020. Available at: https://eaes.eu/eaes-and-sages-recommendationsregarding-surgical-response-to-covid-19-crisis/

10. AORN (Association of PeriOperative Registered Nurses) Guideline 2020. Available at: https://www.aorn.org/guidelines/aorn-support/ covid19-faqs

11. COVID-19 ER Kit. COVID-19 rapid IgG/IgM combined antibody assay. 2020. Available at: https://sensingself.me/covid.php

12. COVID-19 Rapid Antibody Test. 2020. Available at: https://www. biopanda.co.uk/php/products/rapid/infectious_diseases/covid19. php

13. Suriraju V. Postponing of routine surgeries needed amidst corona outbreak. 2020. Available at: https://ehealth.eletsonline.com/2020/ 03/postponing-of-routine-surgeries-needed-amidst-coronaoutbreak/

14. Ficarra V, Novara G, Abrate A, Bartoletti R, Crestani A, De Nunzio $C$ et al (2020) Urology practice during COVID-19 pandemic. Minerva Urol Nefrol 72(3):369-375. https://doi.org/10.23736/ S0393-2249.20.03846-1

15. Bhattacharya K (2020) Are Surgeons in India prepared for COVID19? 2020. Indian J Surg 17:1-2. https://doi.org/10.1007/s12262$020-02185-Z$

16. Wax RS, Christian MD (2020) Practical recommendations for critical care and anesthesiology teams caring for novel coronavirus (2019-nCoV) patients. Can J Anaesth 67:568-576

17. Liana Z, Nadav L, Desire K, Mike A, Satya KR. Anesthesia patient safety foundation. 2020. Available at: https://www.apsf.org/newsupdates/perioperative-considerations-for-the-2019-novelcoronavirus-covid-19/

18. Coccolini F, Perrone G, Chiarugi M, Di Marzo F, Ansaloni L et al (2020) Surgery in COVID-19 patients: operational directives. World J Emerg Surg 15:25

19. Yeo C, Kaushal S, Yeo D (2020) Enteric involvement of coronaviruses: is faecal-oral transmission of SARS-CoV-2 possible? Lancet Gastroenterol Hepatol 5:335-337

20. Quaedackers JSLT, Stein R, Bhatt N, Dogan HS, Hoen L, Nijman RJM et al (2020) Clinical and surgical consequences of the COVID-19 pandemic for patients with pediatric urological problems: Statement of the EAU guidelines panel for paediatric urology, March 30, 2020. J Pediatr Urol 16:284 S1477-5131(20) 30105-4.

21. Vigneswaran Y, Prachand VN, Posner MC, Matthews JB, Hussain M (2020) What is the appropriate use of laparoscopy over open procedures in the current COVID-19 climate? J Gastrointest Surg:1-6
22. Mintz Y, Arezzo A, Boni L, Chand M, Brodie R, Fingerhut A et al (2020) A low cost, safe and effective method for smoke evacuation in laparoscopic surgery for suspected coronavirus patients. Ann Surg 272:e7

23. Zheng MH, Boni L, Fingerhut A (2020) Minimally invasive surgery and the novel coronavirus outbreak: lessons learned in China and Italy. Ann Surg 272:e5 Available at: https://journals.lww.com/ annalsofsurgery/Documents/Minimally $\% 20$ invasive $\% 20$ surgery $\%$

24. Capizzi PJ, Clay RP, Battey MJ (1998) Microbiologic activity in laser resurfacing plume and debris. Lasers Surg Med 1(23):172174

25. Alp E, Bijl D, Bleichrodt RP, Hansson B, Voss A (2006) Surgical smoke and infection control. J Hosp Infect 62:1-5

26. Choi SH, Kwon TG, Chung SK, Kim TH (2014) Surgical smoke may be a biohazard to surgeons performing laparoscopic surgery. Surg Endosc 28:2374-2380

27. Foster P, Cheung T, Craft P, Baran K, Kryskow M, Knowles R et al (2020) Novel approach to reduce transmission of COVID-19 during tracheostomy. J Am Coll Surg S1072-7515(20):30322-30327

28. Lie SA, Wong SW, Wong LT, Wong TGL, Chong SY (2020) Practical considerations for performing regional anesthesia: lessons learned from the COVID-19 pandemic. Can J Anaesth:1-8

29. Ling Y, Xu SB, Lin YX, Tian D, Zhu ZQ, Dai FH et al (2020) Persistence and clearance of viral RNA in 2019 novel coronavirus disease rehabilitation patients. Chin Med J 133:1039

30. Li CI, Pai JY, Chen CH (2020) Characterization of smoke generated during the use of surgical knife in laparotomy surgeries. J Air Waste Manage Assoc 70:324

31. Yu G, Lou Z, Zhang W (2020) Several considerations on the operation of colorectal cancer under the epidemic situation of new coronavirus pneumonia. Chinese J Gastrointestinal Surg 23:9

32. ACS (American College of Surgeons). COVID-19 Guidelines for triage of pediatric patients. March 24, 2020. Available at: https:// www.facs.org/covid-19/clinical-guidance/elective-case/pediatricsurgery

33. Kimmig R, Verheijen RHM, Rudnicki M (2020) for SERGS Council. Robot assisted surgery during the COVID-19 pandemic, especially for gynecological cancer: a statement of the Society of European Robotic Gynaecological Surgery (SERGS). J Gynecol Oncol 31(3):e59

34. Society of European Gynaecological Surgery (SERGS Statement). Statement on the use of robot assisted surgery (RAS) during the COVID-19 pandemic. 2020. Available at: https://www.sergs.org/ media/2020/04/SERGS-Statement-finalApr1.pdf

Publisher's Note Springer Nature remains neutral with regard to jurisdictional claims in published maps and institutional affiliations. 


\section{Affiliations}

S. P. Somashekhar ${ }^{1}$ (D) $\cdot$ Rudra Acharya $^{2} \cdot$ Avinash Saklani $^{3} \cdot$ Devendra Parikh $^{4} \cdot$ Jagdishwar Goud $^{5} \cdot$ Jagannath Dixit $^{6}$. K. Gopinath ${ }^{7}$ - M. Vijay Kumar ${ }^{8} \cdot$ Rajesh Bhojwani $^{9} \cdot$ Sandeep Nayak $^{10} \cdot$ Subramaneswar Rao $^{11} \cdot$ Kiran Kothari $^{12}$.

K. Chandramohan ${ }^{13} \cdot$ Sharad Desai $^{14} \cdot$ Arnab Gupta $^{15}$

1 Department of Surgical Oncology, Manipal Comprehensive Cancer Centre, Manipal Hospitals, Bengaluru, India

2 Max Super-Speciality Hospital, New Delhi, India

3 Tata Memorial Hospital, Mumbai, India

4 HCG Cancer Centre, Ahmedabad, India

5 Yashoda Hospitals, Hyderabad, India

6 HCG, Bengaluru, India

7 HCG Hospitals, Bengaluru, India

8 Yenepoya Medical College, Mangalore, Karnataka, India
9 Santokba Institute of Digestive Surgical Sciences, Santokba Durlabhji Memorial Hospital, Jaipu, India

10 Fortis Cancer Institute, Bangalore, India

11 Indo American Cancer Centre, Hyderabad, India

12 Kothari Onco Surgical Hospital, Ahmedabad, India

13 Department of Surgical Oncology, RCC, Trivandrum 695011, India

14 Mahatma Gandhi Cancer Hospital, Visakhapatnam, India

15 Saroj Gupta Cancer Center and Research Institute, Thakurpukur, Kolkata, India 